\title{
Immunocytochemical expression of tissue specific transcription factor-1 in lung carcinoma
}

\author{
C Di Loreto, V Di Lauro, F Puglisi, G Damante, D Fabbro, C A Beltrami
}

\begin{abstract}
Aims-To investigate the immunocytochemical expression of the tissue specific transcription factor-1 (TTF-1) on cytological specimens of small cell lung carcinoma (SCLC) and to establish its value in the cytological diagnosis of lung cancer. Methods-For each case, the diagnosis was made on cytological specimens and confirmed on subsequent bronchial biopsy specimens. TTF-1 was detected immunocytochemically using the avidinbiotin complex technique with a rabbit antiserum. Expression of TTF-1 was evaluated in 41 cases of SCLC and 17 cases of non-small cell carcinoma (NSCC). The latter were subdivided into eight cases of adenocarcinomas and nine cases of squamous cell carcinomas (SCC).

Results-Positive nuclear immunoreactivity to TTF-1 was identified in $38(92.7 \%)$ of the 41 cases of SCLC, in five $(62.5 \%)$ of eight cases of adenocarcinoma, and one (11\%) of nine cases of SCC. A significant difference was observed between the two main groups, SCLC and NSCC. A comparison between SCLC and adenocarcinoma and SCC showed that TTF-1 expression was significantly different. TTF-1 immunoreactivity was not detected in the inflammatory cells of the same cases.

Conclusions-TTF-1 is strictly associated with SCLC; it was weakly expressed in the various subtypes of NSCC. Although TTF-1 is not specific for SCLC, it can be used to highlight neoplastic cells to good effect when a large inflammatory component is present, and to differentiate SCLC from lymphoid infiltrates.

(F Clin Pathol 1997;50:30-32)
\end{abstract}

C Di Loreto

CA Beltrami

Postgraduate School of Oncology

V Di Lauro

F Puglisi

Department of Biomedical Sciences and Technology G Damante

D Fabbro

Correspondence to Dr Carla Di Loreto Istituto di Anatomia Patologica, Piazzale Santa Maria della Misericordia, 33100 Udine, Italy.

Accepted for publication 13 September 1996 peutic approach to patients with NSCC differs from that in patients with SCLC. In fact, the former may benefit from a surgical approach, but this is not usually the case in the latter. ${ }^{1}$ In addition, combined chemotherapy may induce a complete remission of SCLC because of the high sensitivity of this tumour type to antiblas- tic agents. ${ }^{2}$ Therefore, oncologists need to define tumour type accurately, a task often requiring the use of cytology.

Tissue specific transcription factor- 1 (TTF-1) is expressed by epithelial cells of thyroid, lung, and, during development, by some areas of the brain. ${ }^{3}$ TTF-1 can be detected immunohistochemicaily in human fetal lung as early as 11 weeks of gestation, being localised in the nuclei of epithelial cells of the developing airways. After birth, TTF-1 is selectively expressed in type II alveolar cells and in a subset of bronchiolar epithelial cells of the lung. ${ }^{4}$ TTF-1 activates the transcription of thyroglobulin and thyroperoxidase genes in follicular thyroid cells and the transcription of the surfactant protein genes in alveolar cells. ${ }^{5} \mathrm{~A}$ recent study reported that TTF-1 is immunohistochemically expressed in SCLC. ${ }^{6}$ The present study investigates the potential use of TTF-1 immunostaining to improve the value of cytology in the diagnosis of SCLC.

\section{Methods}

Fifty eight samples of bronchial cytology from 58 patients (mean age, 65.6 years, range $49-93$; male:female ratio, 2.6:1) collected from the files of the Institute of Anatomic Pathology, University of Udine, Italy, were studied. For each case, the diagnosis was made on bronchial cytological material and confirmed on the corresponding biopsy specimens. A total of 41 cases of SCLC, eight cases of adenocarcinoma, and nine cases of squamous cell carcinoma (SCC) were evaluated for TTF-1 immunocytochemical expression. Routinely processed paraffin wax sections from four representative cases of normal lung tissue were also used as controls.

The cytological material was processed for microscopic examination using a cell block technique. ${ }^{7}$ The sputum and bronchial lavage specimens were fixed in $70 \%$ alcohol for 12-24 hours and routinely embedded in paraffin wax. Multiple sections, $5 \mu \mathrm{m}$ thick, were obtained for each case and stained with haematoxylin and eosin for microscopic examination. According to the WHO classification, ${ }^{8}$ SCLC was divided into two subgroups: the classic oat cell carcinoma (12 cases) and the intermediate type (10 cases); the cytological subtype was not determined in 19 cases. TTF- 1 was detected immunocytochemically using a rabbit antiserum to TTF-1. The specificity of this antiserum in immunohistochemical studies has been established before. ${ }^{3}$

Briefly, after rehydration and inhibition of endogenous peroxidase, the sections were 


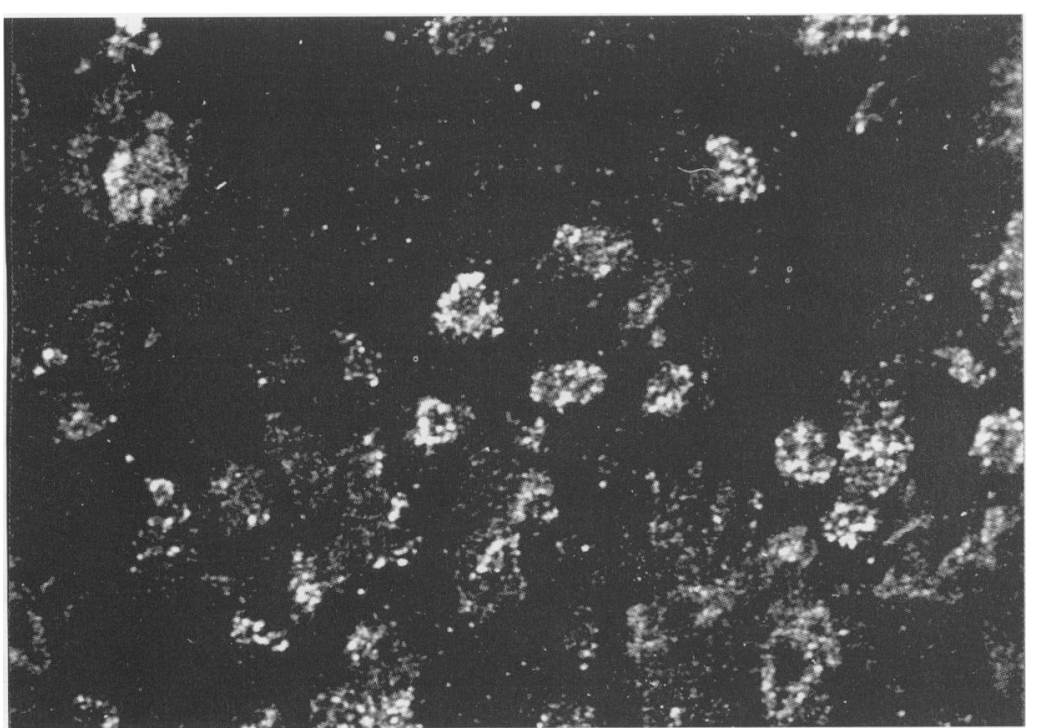

Figure 1 Small cell lung carcinoma: many cells show a strong nuclear granular immunoreactivity for TTF-1. (Fluorescence-confocal laser scanning.)

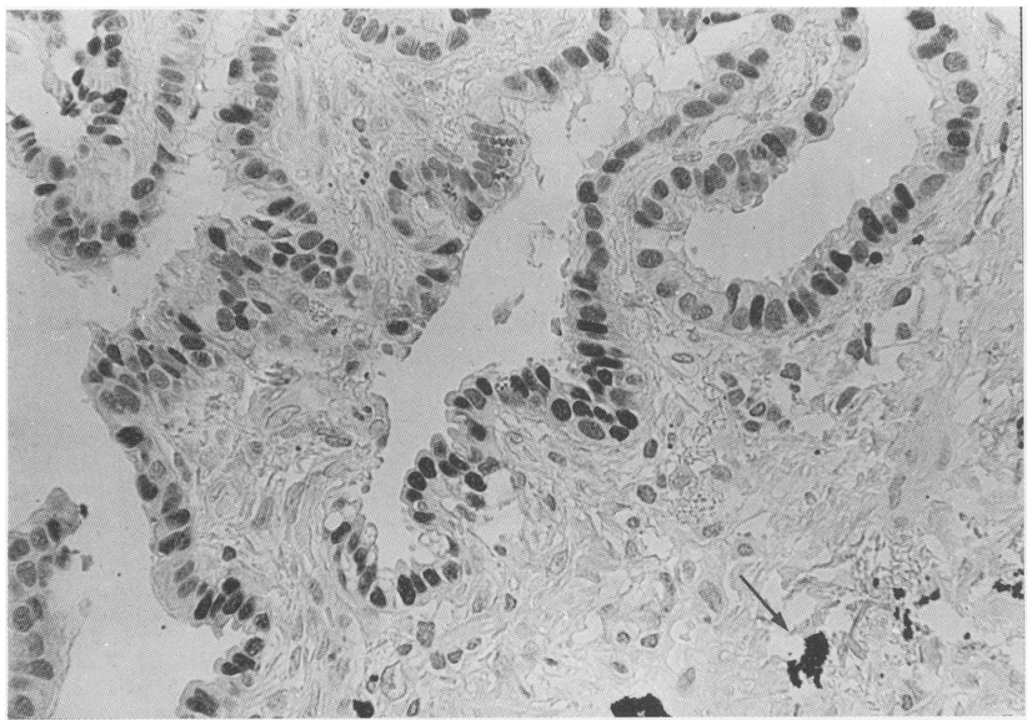

Figure 2 Normal lung tissue showing some bronchiolar epithelial cells with nuclear positivity for TTF-1. Anthracotic deposits can be seen in the interstitium (arrow). (Immunoperoxidase-haematoxylin.)

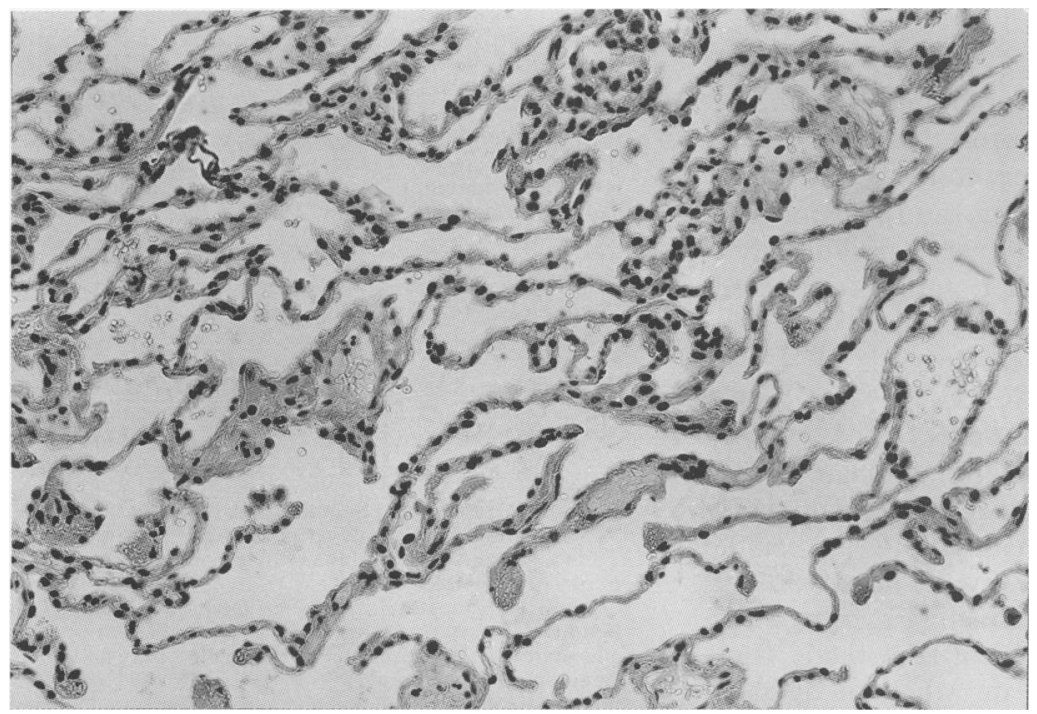

Figure 3 Normal lung tissue showing diffuse nuclear immunoreactivity for TTF-1 in alveolar cells. (Immunoperoxidase-haematoxylin.)

incubated with normal goat serum. Subsequent incubations were as follows (all at room temperature): antibody to TTF-1 diluted 1 in
Table 1 TTF-1 immunoreactivity in small and

non-small cell lung carcinoma

\begin{tabular}{llll}
\hline & $\begin{array}{l}\text { TTF-1 } \\
\text { positive(\%) }\end{array}$ & $\begin{array}{l}\text { TTF-1 } \\
\text { negative(\%) }\end{array}$ & Total \\
\hline SCLC & $38(92.7)$ & $3(7.3)$ & 41 \\
SCC & $1(11)$ & $8(89)$ & 9 \\
AC & $5(62.5)$ & $3(37.5)$ & 8 \\
\hline
\end{tabular}

200 for two hours; biotin labelled goat anti-rabbit for 30 minutes; avidin-biotin peroxidase complex (ABC; Vector Laboratories, Burlingame, California, USA) for 30 minutes; incubation in substrate solution. 3,3'diaminobenzidine was used as the chromogen. The sections were counterstained with light Harris' haematoxylin, dehydrated, cleared, and mounted in Eukitt.

The immunocytochemical preparations were evaluated by two independent observers. The reaction was considered positive if nuclear immunostaining was seen. The percentage of positive cells was evaluated for each immunoreactive case. Fisher's exact test was used for statistical evaluation of the data.

\section{Results}

Immunostaining for TTF-1 was limited to the nuclei of epithelial cells with a finely granular pattern decorating the chromatin, more clearly shown by means of a confocal laser scanning microscope $(0.488 \mu \mathrm{m} / \mathrm{pixel}, \times 40$ objective) (fig 1).

In non-neoplastic tissues, nuclear TTF-1 immunoreactivity was seen in the alveolar and bronchiolar epithelial cells; interstitial cells, lymphocytes, alveolar macrophages did not immunostain for TTF-1 (figs 2-4).

Data about TTF-1 immunoreactivity in lung tumours are summarised in table 1 .

Nuclear immunoreactivity for TTF-1 was identified in neoplastic cells in $38(92.7 \%)$ of the 41 cases of SCLC (fig 5), five $(62.5 \%)$ of the eight cases of adenocarcinoma and in one $(11 \%)$ of the nine cases of SCC. The percentage of positive neoplastic cells in cases of SCLC ranged from $10 \%$ to $100 \%$ (mean 62.2 ; SD 30.1). In TTF-1 positive adenocarcinomas, the percentage of positive cells ranged from $30 \%$ to $80 \%$ (mean (SD) $52(21.7) \%$ ). The immunoreactive case of SCC contained $80 \%$ positive cells. A significant difference in TTF-1 immunoreactivity was found between the two main groups of SCLC and NSCC $(p<0.001)$. When we compared TTF-1 expression in SCLC and adenocarcinoma and SCC, the difference remained significant, with $\mathrm{p}$ values, respectively, of $<0.05$ and $<0.001$.

Inflammatory cells, such as macrophages, neutrophils, and lymphocytes, did not stain for TTF-1.

\section{Discussion}

TTF-1 expression has been investigated both in thyroid and lung tumours. ${ }^{69}$ In contrast to differentiated thyroid carcinomas where TTF-1 is always expressed, in lung carcinomas TTF-1 immunoreactivity varies according to tumour type. A recent study showed that immunostaining for TTF-1 was positive in all 


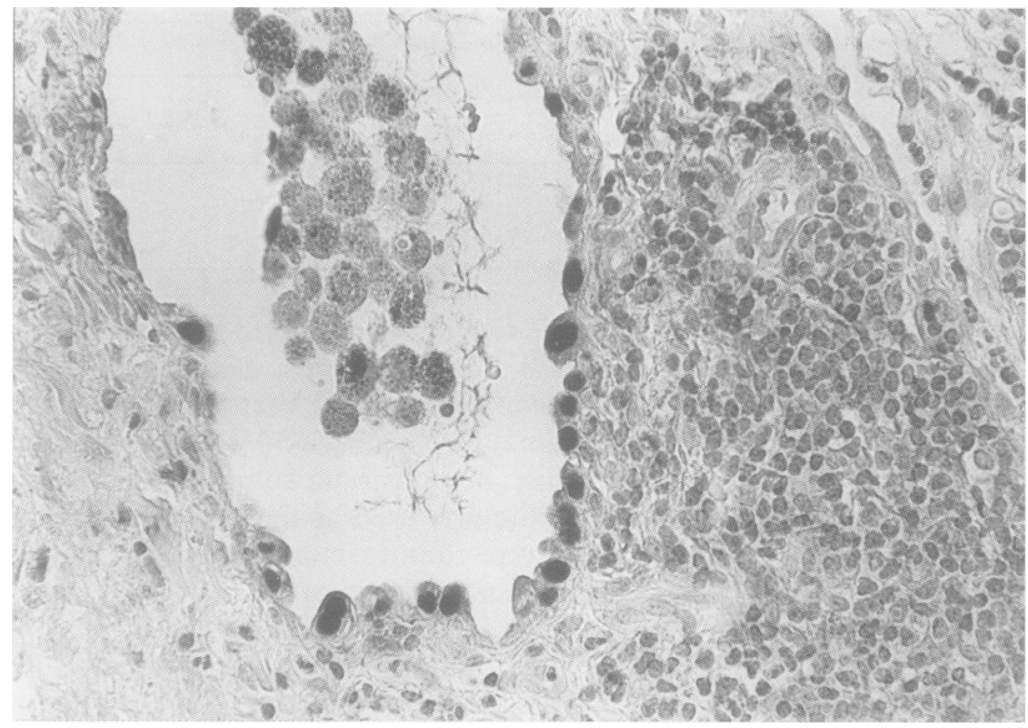

Figure 4 Interstitial pulmonary fibrosis. Alveolar cells are positive for TTF-1 whereas lymphocytes and intra-alveolar macrophages are negative. Note anthracotic pigment in the cytoplasm of macrophages. (Immunoperoxidase-haematoxylin.)

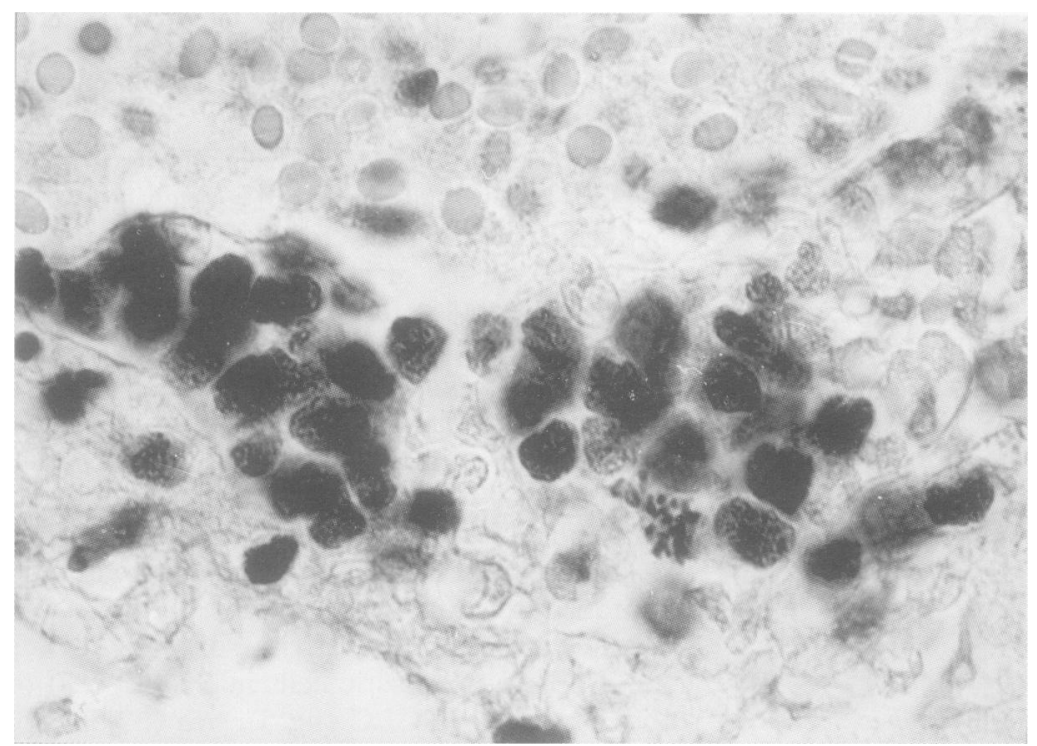

Figure 5 Small cell lung carcinoma: a group of non-cohesive neoplastic cells shows nuclear TTF-1 immunoreactivity. The variable intensity seems to be correlated with chromatinic compactness. The chromosomes of a mitotic figure are also positive.

(Immunoperoxidase-haematoxylin.)

cases of SCLC evaluated on biopsy specimens; the percentage of immunoreactive cells ranged from 54 to $97 \%$. On the contrary, in SCC, bronchioalveolar carcinoma, and adenocarcinoma, positivity for TTF-1 was found in only a few cases. ${ }^{6}$ Recently, other authors reported similar results in NSCC. ${ }^{10}$

In the present cytological series, TTF-1 was expressed in $92.7 \%$ of SCLC, $11 \%$ of SCC, and $62.5 \%$ of adenocarcinomas.

Although TTF-1 is strictly associated with SCLC, our results show its low specificity and, as a consequence, its unsuitability as specific marker of SCLC. However, detection of TTF-1 could be valuable for highlighting neoplastic cells when cytological specimens contain only a few cells, or when neoplastic elements are obscured by inflammatory cells or necrosis.

Furthermore, in some pathological conditions, such as inflammatory diseases or pulmonary lymphomas, small lymphocytes may be misinterpreted as SCLC. As a rule, TTF-1 immunostaining may be used as an ancillary diagnostic method in the differential diagnosis between neoplastic epithelial cells and lymphocytes because of the absence of TTF- 1 in the latter. This is especially valuable when the cytoplasm is absent or not well preserved, and cytoplasmic immunostaining-namely cytokeratins and leucocyte common antigen-does not clarify diagnosis.

The high percentage of positivity observed in adenocarcinoma could also be favourably used to differentiate primary pulmonary adenocarcinoma from metastatic adenocarcinoma, as recently reported by Bejarano et al. ${ }^{10}$

Finally, because of the high prevalence of TTF-1 in SCLC and the differential expression of this marker in NSCC, its potential prognostic role seems to be promising. Indirect support for this hypothesis comes from the findings of the study by Bejarano and colleagues in which TTF-1 and surfactant protein A (SP-A) are shown to be frequently coexpressed in pulmonary tumours. ${ }^{10}$ In fact, in NSCC, surfactant associated protein SP-A and 10 kilodalton Clara cell protein (CC10) have been reported to have prognostic value and, in particular, SP-A is associated with a slower development of metastases. ${ }^{11}$ Furthermore, TTF-1 was recently shown to be involved as a transcription factor in the regulation of surfactant proteins and $\mathrm{CC} 10$ gene expression. ${ }^{512}$

This work was supported by a grant from CNR, ACRO project and AIRC (Associazione Italiana Ricerca sul Cancro). We thank Mrs Di Gaspero Marina for her technical help.

1 Minna JD, Pass H, Glatstein E, Ihde DC. Cancer of the lung. In: De Vita VT, Hellman S, Rosemberg SA, eds. Cancer: principles and practice of oncology. 3rd edn. Philadelphia: JB Lippincott, 1989:591-705.

2 Perry MC, Eaton WL, Propert KJ, Ware JH, Zimmer B, Chahniam AP, et al. Chemotherapy with or without radiation therapy in limited small cell carcinoma of the lung. $N$ Engl f Med 1987;316:912-18.

3 Lazzaro D, Price $M$, De Felice $M$, Di Lauro R. The transcription factor TTF-1 is expressed at the onset of thyroid and lung morphogenesis and in restricted regions of fetal brain. Development 1991;113:1093-104.

4 Ikeda K, Clark JC, Shaw-White JR, Stahlman MT, Boutell CJ, Whitsett JA. Gene structure and expression of human thyroid transcription factor-1 in respiratory epithelial cells. thyroid transcription factor-1 in $1995 ; 270: 8108-14$.

5 Bohinski RJ, Di Lauro R, Whitsett JA. The lung-specific surfactant protein B promoter is a target for thyroid transcription factor 1 and hepatocyte nuclear factor 3, indicating common factors for organ specific gene expression along the foregut. Mol Cell Biol 1994;14:567181

6 Fabbro D, Di Loreto C, Stamerra O, Beltrami CA, Lo Nigro $\mathrm{R}$, Damante G. TTF-1 gene expression in human lung tumours. Eur f Cancer 1996;32A:512-17.

7 Koss Leopold G (ed). Cytologic techniques. In: Diagnostic cytology and its histopathology bases. Vol II. 4th edn. Pytology and its histopathology bases. Vol

8 Koss Leopold G (ed). Tumours of lung: conventional cytology and aspiration biopsy. In: Diagnostic cytology and its histopathology bases. Vol I. 4th edn. Philadelphia: JB Lippincott, 1992:784-5.

9 Fabbro D, Di Loreto C, Beltrami CA, Belfiore A, Di Lauro $R$, Damante $G$. Tissue-specific transcription factors TTF-1 and PAX-8 in human thyroid neoplasms. Cancer Res 1994;54:4744-9.

10 Bejarano PA, Baughman RP, Biddingher PW, Miller MA Fenoglio-Preiser C, Al-Kafajj B, et al. Surfactant proteins and thyroid transcription factor- 1 in pulmonary and breas carcinomas. Mod Pathol 1996;9:445-52.

11 Linnoila RI, Jensen SM, Steinberg SM, Mulshine JM, Eggleston JC, Gazdar AF. Peripheral airway cell marker expression in non-small cell lung carcinoma. Am $\mathfrak{f}$ Clin Pathol 1992;97:233-43.

12 Bohinski RJ, Huffman JA, Whitsett JA, Lattier DL. Cis-active elements controlling lung cell-specific expression of human pulmonary surfactant protein $\mathrm{B}$ gene. $\mathcal{f} \mathrm{Biol}$ Chem 1993;268:11160-6. 